\title{
MICROWAVE AND ULTRASOUNDS TOGETHER - A CHALLENGE
}

\author{
M. Vinatoru, I. Calinescu
}

University Politehnica of Bucharest, Faculty of Applied Chemistry and Materials Science, Bioresources and Polymer Science Department, 1-7 Gh. Polizu Str., 011061, Bucharest, Romania

Emails: mircea.vinatoru@upb.ro;ioan.calinescu@upb.ro;

Keywords: microwave, ultrasound, equipment, combined MW-US

\section{Introduction.}

If we are looking on each energy effects (MW, US) on a system, we could easily see that:

- Microwave effect on a homogenous system produce volumetric heating as well as quick heating;

- Microwave effect on a heterogenous system produce selective heating of phases.

- Ultrasonic effect on a homogenous system produce radical active species (influencing many chemical reactions, especially those implying electron transfer);

- Ultrasonic effect on a heterogenous system produce mass transfer intensification and surface effects (erosion, cleaning, catalyst activation, etc.).

Based on these facts it is obvious that a combination of these two forms of energy and their effects are quite exciting among chemists, and from here to making such a combination was just a step. The idea of combining MW with US was probably older than 1999 when the first paper on this topic was published [1], but the accessibility to shelf acquirable apparatus was not possible. Like in many other laboratory trials the first apparatus of this kind was inhouse build.

It was the paper of Lionelli and Mason [2], which after separately introducing theoretical and scientific facts for microwaves and sonochemistry, along with their applications as an individual sources of energy (totally different: microwave is an electromagnetic energy while acoustic energy is mostly a mechanical energy, however generated via electromagnetic waves), several pictures of combination between a microwave and an ultrasonic device described already in the literature were presented. In their paper is stated that two styles of combining microwave with ultrasound were used at that time:

- $\quad$ Separate reactors (MW and US) with a pump to allow the liquid to be transferred from one reactor to another and

- $\quad$ Single reactor with both US and MW inside.

Both type of reactors is nowadays available for laboratory lab scale.

Searching the literature using Scopus with as key words: microwave, ultrasound, combined and chemistry returns 192 documents result. Adding to the keywords "simultaneous" the number of documents drop to 86. Of course, the more general searching engines returns much more documents, but many of them irrelevant to the search topic. The main challenge in making a machine to be able to use combined and/or simultaneously both source of energy is related to the concept of inserting ultrasound into a microwave unit or vice versa.

In the first report on combining ultrasound with microwaves published in 1999 by Lagha et. al. [1], it was shown (see figure 1 [1]) how a magnetron insert microwaves in a rector having an ultrasonic cup-horn device mounted on the bottom of the wave guide, decalin being used as US coupling liquid. 


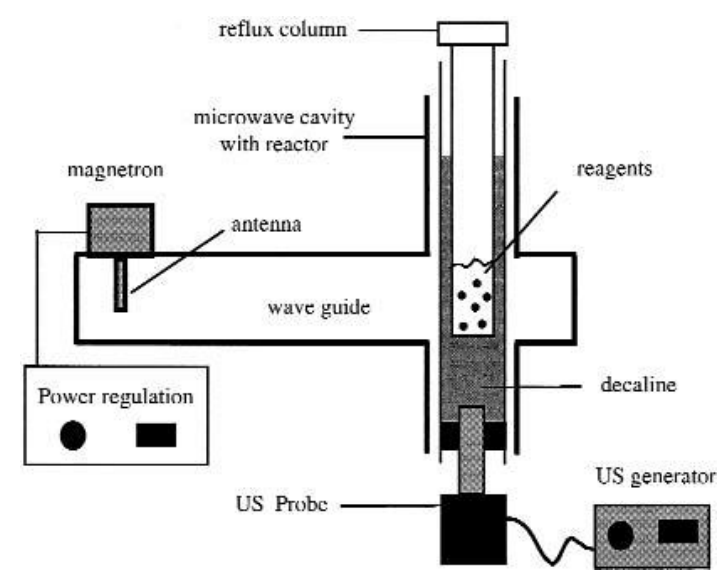

Figure 1. Schematic drawing of the single mode microwave system combined with ultrasound (after Lagha et. al. [1])

The combined microwave and ultrasound apparatus decreased the digestion and dissolution time of samples for analytical purposes. Similar device was employed for analytical sample preparation purpose (determination of copper in edible oil and total Kjeldahl nitrogen) via digestion assisted by microwave and ultrasound apparatus [3].

In a paper published in 2001 another arrangement of the two sources of energy in one machine is proposed by Peng et. al. figure 2 [4]:

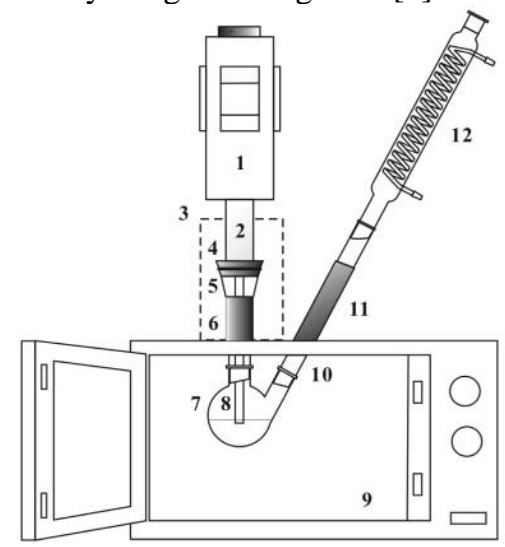

1. Transducer housing;

2. Upper horn;

3. Copper mesh screen;

4. Rubber stopper;

5. Adaptor;

6. Port;

7. Two-necked Pyrex flask;

8. Detachable horn;

9. Multimode cavity;

10. Adaptor;

11. Chock;

12. Condenser

Figure 2. Apparatus for microwave-ultrasound combined reactions (after Peng et. al. [4]).

In this approach a microwave oven (multimode cavity) was transformed to adapt to it a classic ultrasonic horn device. To prevent radiation leakage a copper mesh screen was settled around the ultrasonic horn. This device was successfully used to prepare hydrazides by hydrazinolysis of the corresponding esters with hydrazine monohydrate. The same device was used to synthesis of 3-aryl acrylic acids in good yields via Knoevenagel-Doebner reaction [5] in a solvent-free protocol.

Cravotto et. al. used US and MW in a different way [6, 7]. The ultrasonic probe reactor is placed outside of microwave oven and a tube connect the reaction mixture to both sources of energy (figure 3): 


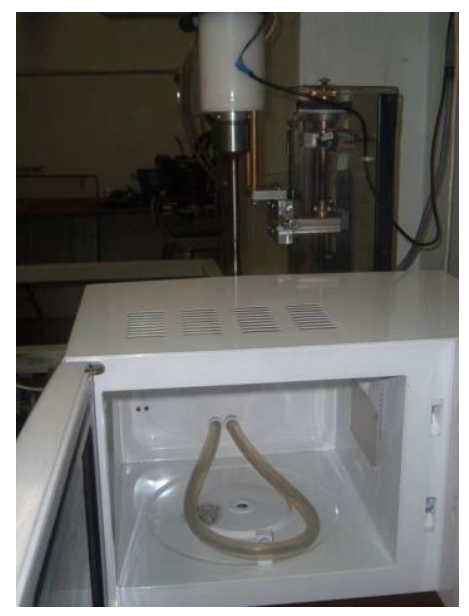

Figure 3. Reactor prototype featuring combined US/MW irradiation [6].

The such of combined devices was used to carry out ligand-free Pd/C-catalyzed Suzuki cross- and homocouplings reaction in aqueous media.

Cintas and Cravotto wrote in 2007 a paper about Ultrasound and Microwaves in Chemistry: A Relay Race or Tandem? The Combined Use of Microwaves and Ultrasound: Improved Tools in Process Chemistry and Organic Synthesis [8]. Among devices that combine microwave with ultrasound, perhaps the simplest is the one in which ultrasonic irradiation is inside of a single vessel provided by a quartz (or glass) made horn which can be inserted into microwave oven (figure 4 [8]):

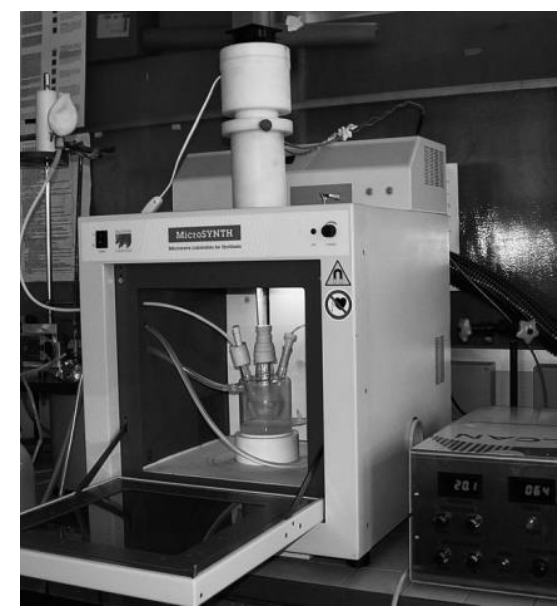

Figure 4. Simultaneous irradiation in a multimode MW oven equipped with a Pyrex horn [8]. 
Although quartz or glass is fragile and the ultrasonic power entering into a reaction mixture cannot be too high, it is probably the best combination for simultaneous uses of both energies. Though there are not too many papers published so far in this field, MW coupled with US in one machine (or a sequential one) the attention for having two energies interacting differently with materials, is raising.

Cravotto, prosed in the same time period (2007) another type of combined MW-US reactor [9], a "flow" reactor for the treatment of polluted water. The word "flow" was not adequately used for this reactor, actually it is a batch type reactor, with a limited tank volume holding the initial solution to treat. It is having not inlet/outlet points for solution to make it a real "flow" reactor, but clearly makes possible treatment using both energies features.

Using a cup-horn or probe ultrasonic device, with different frequencies (19, 25, 40 and 300 $\mathrm{kHz}$ ), Cravotto et. al. successfully extracted soybean germs or algae oil in a simultaneous US/MW (multimode oven) developed apparatus. The authors concluded that techniques using US or combined US/MW irradiation should be well suited for other processes, such as two step one: extraction and transesterification for biofuel purpose [10].

In an apparatus similar with those described in figure 1, Shen [11] proposed a rapid synthesis of $\mathrm{Pb}(\mathrm{OH}) \mathrm{Br}$ nanowires. Heating alone provide $0.02-0.03 \mathrm{~mm}$ diameter and $2-3 \mathrm{~mm}$ length nanowires, while MW $(50 \mathrm{~W})$ the diameter is ten times smaller and rather short nanowires. US alone further reduce the diameter as well as the length of the nanowires. Combining MW and US $(50 \mathrm{~W}-50 \mathrm{~W})$ the diameter drops to $80-800 \mathrm{~nm}$, and the length to $50-100 \mu \mathrm{m}$. If the MW power is higher $-250 \mathrm{~W}$, (higher heating contribution) and US power maintained the same, the diameter narrowed $(100-500 \mathrm{~nm})$ while the length became rather short Table 1 in reference [11]).

After 2010 a number of papers were published having as topic either two steps processes, like metal organic framework IRMOF-1 synthesis [12], (in a separate reactors as stated by Lionelli and Mason), synthesis of polysubstituted pyridines under combined microwave and ultrasound irradiation [13], porous manganese dioxide $\left(\mathrm{MnO}_{2}\right)$ synthesized via an ultrasound-microwave-intensified precipitation [14] (perhaps in a single reactor - the papers do not offers details of equipment), or even for biodiesel preparation emphasizing the synergetic effects of combining both source of energy in one device [15]. Several papers shown how to build or review the simultaneous ultrasound and microwave new reactor [1619], others how to use this combination for adding value to some byproducts (like glycerol from biodiesel synthesis) [20]. Clearly there are efforts in developing such a combined device in which MW and US could be used together in a controllable mode.

Our group is having at least one of the equipment capable to work in single reactor with both US and MW [2], but different from the apparatus presented in the paper. This device is produced by SAIREM and is described in a paper published few years ago by Sacco et. al., [17] as a hybrid technology applicable for a specific process (ring closing metathesis) and is in use in our laboratory from a couple of years. This device is having as ultrasonic source a modified ultrasonic cleaning bath to be attachable to the MW unit (see figure 5). 


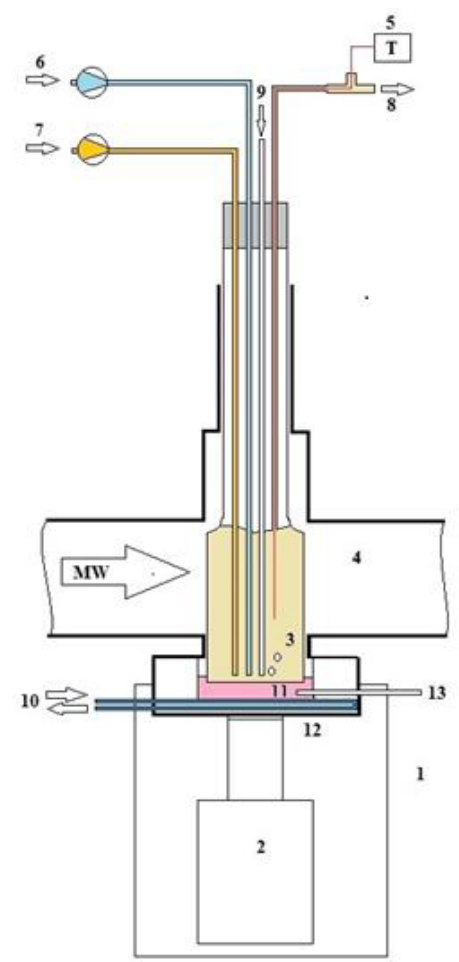

1. Ultrasonic bath

2. Transducer

3. Reactor

4. Waveguide

5. Temperature control

6. Methanol inlet

7. Oil inlet

8. Reaction products outlet

9. Gas flow

10. Cooling agent

11. Paraffin oil

12. Cooling coil

13. Thermometer

Figure 5. Miniflow US + MW simultaneous microwaves-ultrasound irradiation.

This setup was successfully employed for biodiesel synthesis using simultaneous MW-US irradiation. The conversion of sunflower oil to methyl fatty acids esters (FAME) being over 97\% (EU norm for an accepted for a transesterification process [21] imposes at least $96.5 \%$ concentration of FAME at the end of process).

The only problem that we encountered using this device in some of laboratory experiments was that the US power control is lacking and therefore the device is working on full US power and adjustable MW power. Fortunatley the development in the ultrasonic devices construction allow a new type of ultrasonic device (clamp-on [22]) to be attachable to a flow through pipe, like in the figure 6 below (device existent in our laboratory), and therefore building a hybrid machine able to work with both powers on full control. 


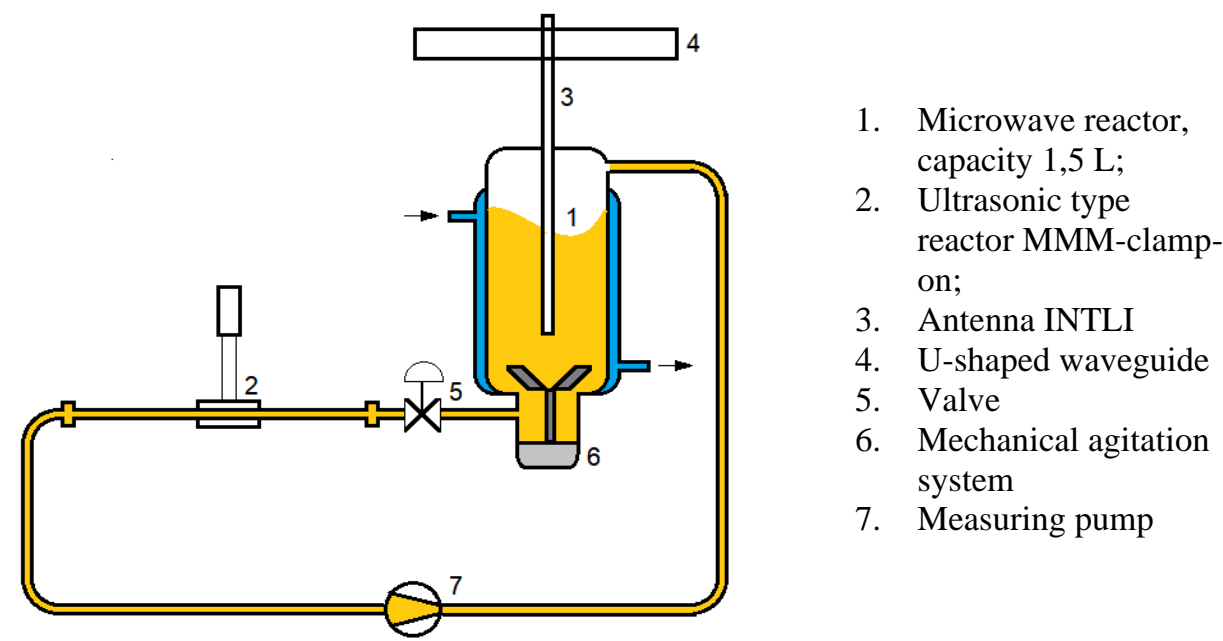

Figure 6. MW and US in a close loop configuration

\section{Conclusions}

The simultaneous or combined uses of microwaves and ultrasound is a solution (perhaps a very good one) for physical and/or chemical processes intensification [23, 24]. The microwaves ensure a speeding of the reaction rate via selective or volumetric heating (depending of the reaction mixture types: homogenous or heterogenous), while ultrasound enhance the mass transfer between phases, ensures better mixing and allow a better distribution of temperature in homogenous media. Combining these two sources of energy it may be possible to assist to the naissance of a synergetic hybrid technology [2], fully controllable and usable in the laboratories, pilot and why not industrial scales.

The difficulties we face now are challenging and hopefully at least at laboratory scale will be overcome. The first challenge is that microwaves heat up the reaction mixture, while ultrasound is known by its paradoxical effects - lower the temperature better effects. What kind of reactions/processes will benefit from this hybrid technology? The time and reactions/processes selections and experiments will show which one is privileged by this. We may advance here the idea that heterogenous reactions/processes could be the ideal candidate for such of technology.

There is obvious that we need to overcome also the lack of coherent mathematical models to be used for simulation MW and US features in one application.

Scaling up of both techniques is very difficult and this difficulty increases when we will put together MW and US. However, using the new concept of numbering up instead of scaling up [25] we are confident that soon we will step towards a new exciting hybrid technology, applicable to any scale.

\section{Aknowledgements}

The authors acknowledge the financial support received from the Competitiveness Operational Programme 2014-2020, Action 1.1.4: Attracting high-level personnel from abroad in order to enhance the RD capacity, project: P_37_471, „Ultrasonic/Microwave Nonconventional Techniques as new tools for nonchemical and chemical processes", financed by contract: 47/05.09.2016 


\section{References}

[1]. A. Lagha, S. Chemat, P. V. Bartels and F. Chemat, Analusis, 27(5) (1999) 452457 https://doi.org/10.1051/analusis:1999124.

[2]. C. Leonelli and T. J. Mason, Chemical Engineering and Processing: Process Intensification, 49(9) (2010) 885-900 https://doi.org/10.1016/j.cep.2010.05.006

[3]. S. Chemat, A. Lagha, H. Ait Amar and F. Chemat, Ultrasonics Sonochemistry, 11(1) (2004) 5-8 https://doi.org/10.1016/S1350-4177(03)00128-7.

[4]. Y. Peng and G. Song, Green Chemistry, 3(6) (2001) 302-304 https://doi.org/10.1039/b108878p.

[5]. Y. Peng and G. Song, Green Chemistry, 5(6) (2003) 704-706 https://doi.org/10.1039/b310388a.

[6]. G. Cravotto, M. Beggiato, A. Penoni, G. Palmisano, S. Tollari, J. M. Lévêque and W. Bonrath, Tetrahedron Letters, 46(13) (2005) 2267-2271 https://doi.org/10.1016/i.tetlet.2005.02.015.

[7]. G. Cravotto and P. Cintas, Chemical Society Reviews, 35(2) (2006) 180-196.

[8]. G. Cravotto and P. Cintas, Chemistry - A European Journal, 13(7) (2007) 19021909 https://doi.org/10.1002/chem.200601845.

[9]. G. Cravotto, S. Di Carlo, M. Curini, V. Tumiatti and C. Roggero, Journal of Chemical Technology and Biotechnology, 82(2) (2007) 205-208 https://doi.org/10.1002/jctb.1658.

[10]. G. Cravotto, L. Boffa, S. Mantegna, P. Perego, M. Avogadro and P. Cintas, Ultrasonics Sonochemistry, 15(5) (2008) 898-902 https://doi.org/10.1016/j.ultsonch.2007.10.009.

[11]. X. F. Shen, Journal of Chemical Technology and Biotechnology, 84(12) (2009) 1811-1817 https://doi.org/10.1002/jctb.2250.

[12]. R. Sabouni, H. Kazemian and S. Rohani, Chemical Engineering Journal, 165(3) (2010) 966-973 https://doi.org/10.1016/j.cej.2010.09.036.

[13]. H. Feng, Y. Li, E. V. Van Der Eycken, Y. Peng and G. Song, Tetrahedron Letters, 53(9) (2012) 1160-1162 https://doi.org/10.1016/j.tetlet.2011.12.103.

[14]. P. Wang, Y.-J. Zhao, L.-X. Wen, J.-F. Chen and Z.-G. Lei, Industrial \& Engineering Chemistry Research, 53(52) (2014) 20116-20123 dx.doi.org/10.1021/ie5025485.

[15]. E. Martinez-Guerra and V. G. Gude, Fuel, 137 (2014) 100-108 https://doi.org/10.1016/j.fuel.2014.07.087.

[16]. V. Ragaini, C. Pirola, S. Borrelli, C. Ferrari and I. Longo, Ultrasonics Sonochemistry, 19(4) (2012) 872-876 https://doi.org/10.1016/j.ultsonch.2011.12.008.

[17]. M. Sacco, C. Charnay, F. De Angelis, M. Radoiu, F. Lamaty, J. Martinez and E. Colacino, RSC Advances, 5(22) (2015) 16878-16885 https://doi.org/10.1039/c4ra14938f.

[18]. P. Cintas, S. Tagliapietra, M. Caporaso, S. Tabasso and G. Cravotto, Ultrasonics Sonochemistry, 25(1) (2015) 8-16 https://doi.org/10.1016/j.ultsonch.2014.12.004.

[19]. K. Martina, S. Tagliapietra, A. Barge and G. Cravotto, Combined Microwaves/Ultrasound, a Hybrid Technology, in Topics in Current Chemistry. 2016.

[20]. P. Cintas, S. Tagliapietra, E. Calcio Gaudino, G. Palmisano and G. Cravotto, Green Chemistry, 16(3) (2014) 1056-1065 https://doi.org/10.1039/c3gc41955j. 
[21]. Liquid petroleum products - Fatty acid methyl esters (FAME) for use in diesel engines and heating applications - Requirements and test methods in DIN EN 14214, E. Standards, Editor. 2014.

[22]. Ultrasonics.com Available from: https://www.mpiultrasonics.com/content/clamp-ultrasonic-systems.

[23]. A. Stankiewicz and J. A. Moulijn, Industrial \& Engineering Chemistry Research, 41(8) (2002) 1920-1924 https://doi.org/10.1021/ie011025p.

[24]. A. I. Stankiewicz and J. A. Moulijn, Chemical engineering progress, 96(1) (2000) 22-34.

[25]. D. Fernandez Rivas and S. Kuhn, Synergy of Microfluidics and Ultrasound: Process Intensification Challenges and Opportunities, in Topics in Current Chemistry. 2016. 